Ford, A., Almeida, O., Flicker, L., De Garrido, G., Greenop, K., Foster, J. K., ... Lautenschlager, N. (2014). Grey matter changes associated with deficit awareness in mild cognitive impairment: A voxel-based morphometry study. Journal of Alzheimer's Disease, 42(4), 1251-1259.

(C) 2014 - IOS Press and the authors. All rights reserved

This is pre-copy-editing, author-produced version of an article accepted for publication in Journal of Alzheimer's Disease, following peer review. The definitive published version (see citation above) is located on the article abstract page of the publisher, IOS Press.

This version was made available in the UWA Research Repository on 26 May 2015 in compliance with the publisher's policies on archiving in institutional repositories.

Use of the article is subject to copyright law. 


\section{Grey Matter Changes Associated with Deficit Awareness in Mild Cognitive Impairment: A Voxel-based Morphometry Study}

Andrew H. Ford ${ }^{\mathrm{a}, \mathrm{b}}$, Osvaldo P. Almeida ${ }^{\mathrm{a}, \mathrm{b}}$, Leon Flicker ${ }^{\mathrm{a}, \mathrm{c}}$, Griselda J. Garrido ${ }^{\mathrm{a}}$, Kathryn R. Greenop $^{\mathrm{a}, \mathrm{d}}$, Jonathan K. Foster ${ }^{\mathrm{e}}$, Christopher Etherton-Beer ${ }^{\mathrm{a}, \mathrm{c}}$, Frank M. van Bockxmeer ${ }^{\mathrm{f}}$, Nicola T. Lautenschlager ${ }^{\mathrm{a}, \mathrm{b}, \mathrm{g}}$

\footnotetext{
${ }^{a}$ Western Australian Centre for Health \& Ageing (M573), Centre for Medical Research, University of Western Australia, 35 Stirling Highway, Crawley, Perth, WA, 6009, Australia

${ }^{\mathrm{b}}$ School of Psychiatry and Clinical Neurosciences, University of Western Australia, 35 Stirling Highway, Crawley, Perth, WA, 6009, Australia

c School of Medicine and Pharmacology, University of Western Australia, Perth, WA, Australia

${ }^{\mathrm{d}}$ Telethon Institute for Child Health Research, University of Western Australia, Perth, WA, Australia

e School of Psychology and Speech Pathology, Curtin University, Perth, WA, Australia

${ }^{\mathrm{f}}$ School of Pathology \& Laboratory Medicine, University of Western Australia, Perth, WA, Australia

${ }^{\mathrm{g}}$ Academic Unit for Psychiatry of Old Age, St. Vincent's Health, Department of Psychiatry, St. George's

Hospital, The University of Melbourne, 283 Cotham Road, Kew, Victoria, 3103, Australia
}

Running title: Insight and Mild Cognitive Impairment

Correspondence to: Dr Andrew H Ford, Western Australian Centre for Health \& Ageing (M573), University of Western Australia, 35 Stirling Highway, Crawley, WA 6009, Australia.

Telephone: +61-8-92242855 Fax: +61-8-92248009

E-mail: andrew.ford@uwa.edu.au 


\begin{abstract}
Reduced awareness of cognitive deficits in mild cognitive impairment is associated with poorer outcomes although little is known about the anatomical correlates of this. We examined the association of insight and grey matter volume using a voxel-based morphometry approach in 65 volunteers with mild cognitive impairment and 55 healthy age matched controls. Participants with mild cognitive impairment had multiple areas of subtle grey matter volume loss compared with controls although these did not survive correction for multiple comparisons. These were predominantly in the temporal and anterior portions of the brain. Individuals with mild cognitive impairment did not differ from each other on a number of demographic and cognitive variables according to level of insight. Reduced awareness of cognitive deficits was associated with few differences in grey matter volume apart from a subtle loss of grey matter in the medial frontal gyri. Given the modest nature of these findings, the routine assessment of insight in non-clinical populations of individuals with mild cognitive impairment is therefore not supported. Prospective data in larger samples however would be helpful to clarify this further and determine if impaired insight predicts brain atrophy and cognitive decline.
\end{abstract}

Keywords: Mild cognitive impairment, awareness, grey matter, insight 


\section{INTRODUCTION}

Mild cognitive impairment (MCI) is a clinical syndrome characterized by subjective and objective cognitive impairment, relatively preserved functioning and absence of dementia [1]. For many people, MCI represents a transition between normal cognitive function and dementia, with an annual conversion rate to Alzheimer's dementia in clinical samples of around $12 \%$ in the amnestic subtype [2]. There are currently no effective therapies to prevent or delay conversion to dementia [3], although the identification of biomarkers aimed at detecting the earliest stages of Alzheimer's disease has become a recent focus of research [4]. However, many people with MCI do not progress to dementia and might even improve, perhaps reflecting the diverse etiology and heterogeneous nature of the syndrome [5].

Anosognosia, or reduced awareness of deficits, is a not uncommon among people with MCI $[6,7]$. Its presence might contribute to delay in diagnosis and appropriate support, and may be a negative prognostic indicator, with some studies suggesting an increased risk of progression of cognitive deficits over time in those with reduced awareness of functional and cognitive problems $[8,9]$.

Anosognosia has been associated with brain changes in dementia and MCI. A review of 18 studies examining the anatomical correlates of anosognosia in dementia [10] showed that various brain regions might be involved, more commonly those affecting anterior portions of the cerebrum. Only two of these studies used structural imaging, with self-appraisal of cognitive performance being correlated with grey matter density in the right ventromedial prefrontal cortex [11] and anosognosia correlated with relative grey matter loss in the right superior temporal sulcus [12]. Two small functional imaging studies in MCI showed subtly 
attenuated cortical midline structure activity during self-appraisal tasks [13] and reduced cerebral blood flow in the right inferior central gyrus [14].

To the best of our knowledge, no previous studies have examined the association between grey matter volume and awareness of deficits in MCI using a voxel-based morphometry (VBM) approach. The aims of the present study were two-fold: (1) to compare grey matter volume of MCI participants with controls and, (2) to determine if awareness of cognitive deficits is associated with regional grey matter loss in participants with MCI.

\section{METHODS}

Study design

This is a cross-sectional imaging analysis of the Perth Perception Study (PEPERS). The PEPERS study was a single-site 18 -month observational study of 183 community volunteers (92 participants with MCI and 91 controls) that aimed to determine the prevalence of reduced awareness of cognitive deficits and if this reduced awareness was associated with cognitive decline over the 18 months. The main findings of the study have been reported elsewhere [15]. The current investigation is limited to the baseline data of participants who consented to undergo this substudy ( $\mathrm{n}=120)$ of magnetic resonance imaging (MRI). Data were collected between February 2005 and December 2007 in Perth, Western Australia, and all participants provided written informed consent. The study complied with the principles of the Helsinki Charter for Human Rights and was approved by the Ethics Committees of the University of Western Australia and Royal Perth Hospital. 


\section{Participants}

Recruitment and participant characteristics have been described [15]. In brief, participants were community-dwelling volunteers aged 65 and over who had a reliable informant available. MCI was considered to be present when volunteers answered "yes" to the question “do you have problems or difficulty with your memory?" and scored 1.5 standard deviations or greater below age and gender appropriate normative values on any item of the Consortium to Establish a Registry for Alzheimer's Diseases (CERAD) neuropsychological battery [16]. Participants were excluded if they scored $<19$ on the Telephone Interview for Cognitive Status-Modified (TICS-m) [17] or had a diagnosis of dementia, used alcohol in a harmful manner ( 5 or more standard drinks per day on a regular basis or 6 or more standard drinks on any one occasion), had clinically significant depressive symptoms as evidenced by a score of $\geq 7$ on the Geriatric Depression Scale (GDS-15) [18], or were not fluent in written and spoken English. Additional exclusion criteria included uncorrected sensory impairment, past history of stroke, recent myocardial infarction and severe medical illness likely to compromise survival over the 18 months (e.g., metastatic cancer). Controls denied subjective memory problems and did not show evidence of cognitive impairment on the CERAD.

\section{Assessment of awareness of deficits}

Participants and informants completed the Anosognosia Questionnaire-Dementia (AQ-D) [19]. The AQ-D comprises 30 questions covering aspects of memory, activities of daily living and non-cognitive symptoms. Each item is marked out of a score of 0-3, yielding a total maximum score of 90 (higher scores indicate greater impairment). A discrepancy score (informant score minus participant score) is used as a measure of self-awareness, with higher scores indicating increasing reduced awareness. For the purposes of this study, we created a categorical variable of anosognosia, and considered that participants had impaired awareness 
of cognitive deficits if their anosognosia discrepancy score was greater than one standard deviation (SD) above the sample mean. We also considered that those with a discrepancy score lower than one SD from the mean were overly concerned about their cognitive performance. Those scoring within a SD either side of the mean were classified as having an appropriate level of awareness (or intact insight).

\section{Additional variables of interest}

Participants were assessed telephonically (to assess for eligibility) and face-to-face. Demographic, lifestyle and clinical data were obtained at both of these assessments. This included participants' age, gender, education (years of formal education), estimated premorbid intelligence quotient (IQ) and health related quality of life (SF-36). Cognitive variables of interest were the Mini-Mental State Examination (MMSE) [20] and the Alzheimer Disease Assessment Scale - Cognitive Subscale (ADAS-cog) [21].

\section{Biochemical data}

We collected fasting blood samples between 08:00 and 09:00 at the Royal Perth Hospital Department of Biochemistry and these were processed immediately to extract plasma and serum, which were then batched and stored at $-80^{\circ} \mathrm{C}$ until assayed. Apolipoprotein E (APOE) genotyping followed routine procedures [22]. Total plasma homocysteine concentration was determined by reverse phase high performance liquid chromatography after treatment with tributylphosphine, deproteinization and fluorogenic derivatization [23]. Serum $\mathrm{B}_{12}$ and red

cell folate were measured by standard competitive assays using the Abbott Axsym analyzer. The coefficient of variation ranged from $3 \%$ to $7 \%$. 


\section{Image acquisition}

Brain images were acquired with a 1.5 Tesla Siemens ${ }^{\circledR}$ Symphony MRI scanner (TR: 2830 ms, TE: 4.48 , flip angle: $15^{\circ}$, matrix size: $256 \times 256 \times 172$, voxel size: $0.9 \mathrm{~mm}^{3}$ ) within 4 weeks of the clinical assessment. DICOM data were then converted to NIfTI file format using MRIcron (http://www.mricron.com).

\section{Voxel-based morphometry}

We used Statistical Parametric Mapping version 8 (SPM8) software

(http://www.fil.ion.ucl.ac.uk/spm) to process the data on Matlab ${ }^{\circledR} 2012 \mathrm{~b}$ (version 8.0.0.783). Images were visually inspected for defects or artifact before processing. T1-weighted images were segmented into grey matter (GM), white matter (WM) and cerebral spinal fluid (CSF) using the standard segmentation sequence in SPM. A GM template was created from all patients using the DARTEL toolbox included in SPM. GM data was spatially normalized and warped in DARTEL and transformed to Montreal Neurological Institute (MNI) space (http://www.mni.mcgill.ca). Images were then smoothed with an $8 \mathrm{~mm}$ full-width half maximum (FWHM) Gaussian kernel. The smoothed, modulated, normalized GM datasets were used in the statistical analysis. Total intracranial volume (ICV) was calculated for each participant by summing the total tissue probability of GM, WM and CSF.

Regional grey matter volume differences according to MCI status and level of awareness were assessed using the SPM8 general linear model based on random Gaussian field theory. Level of awareness was included as both a categorical and continuous variable, utilizing a two-sample $\mathrm{t}$ test and multiple regression design respectively. We used the SPM masking toolbox (http://www0.cs.ucl.ac.uk/staff/g.ridgway/masking/) to create an explicit mask, thresholded using correlation-based optimality criteria as described by Ridgway et al. [24]. 
Significant effects were assessed using a voxelwise uncorrected threshold of $p \leq 0.005$ and clusters regarded as significant if they were larger than 100 voxels. A mean image of the dataset was created from the normalized native space images and used as a template for visual presentation of these differences. Age and intracranial volume were included as covariates in the models.

\section{Statistical analysis}

Data were analyzed with Stata version 12.1 (StataCorp, Texas). Descriptive statistics were used to investigate the distribution of data according to MCI and insight status. Normality of distribution was determined visually using histograms and statistically with the KolmogorovSmirnov test. Means and standard deviations were used to describe normally distributed continuous variables, medians and inter-quartile ranges for ranked variables and frequencies and percentages for categorical variables. Student t-tests or analysis of variance (ANOVA) were used to compare normally distributed continuous variables and the Mann-Whitney or Kruskall-Wallis test was used for data without a normal distribution. Chi-squared tests were used to compare proportions between groups.

\section{RESULTS}

\section{Population characteristics}

Table 1 summarizes the characteristics of the study population. Participants with mild cognitive impairment were younger than controls $(\mathrm{z}=3.43, \mathrm{p}<0.001)$, had worse quality of life $(\mathrm{z}=3.52, \mathrm{p}<0.001)$ and lower premorbid intellectual functioning $(\mathrm{z}=3.99, \mathrm{p}<0.001)$. They also, predictably, scored lower on tests of cognitive functioning.

\section{TABLE 1}


We then compared participants with MCI according to their level of insight: intact, overly concerned or impaired (Table 2). Participants in these groups were well matched for demographic variables and measures of cognitive function. The finding of reduced tHcy concentration in the concerned group was interesting and did not appear to be explained by serum $\mathrm{B} 12(\mathrm{~F}=1.14, \mathrm{p}=0.328)$ or red cell folate $(\mathrm{F}=1.24, \mathrm{p}=0.296)$ concentrations. There were no differences in total grey matter volume among participants in these groups $(\mathrm{F}=0.09$, $\mathrm{p}=0.913)$.

\section{TABLE 2}

\section{MRI findings: regional grey matter changes}

People with MCI had multiple areas of grey matter volume loss compared with controls

(Figure 1): left inferior and middle frontal gyri (cluster size=1143; Montreal Neurological Institute coordinates $[\mathrm{MNI}]$ in $\mathrm{mm}-42,27,-9, \mathrm{t}=3.49$; MNI $-40,41,-11, \mathrm{t}=3.4$; MNI $-22,17$, $20, t=3.35$ ), the left uncus and middle temporal gyrus (cluster size=1032; MNI $-34,-4,-35$, $\mathrm{t}=3.32$; MNI -24, -9, -38, $\mathrm{t}=3.11$; MNI -30, 3, -35, t=3.09), left hippocampus (cluster size $=417, \mathrm{MNI}-32,-37,-2, \mathrm{t}=3.73$ ), right middle temporal gyrus (cluster size $=346, \mathrm{MNI} 69,-$ $18,-18, \mathrm{t}=3.64$ ), right temporal fusiform gyrus (cluster size=306, MNI 46, $-3,-29, \mathrm{t}=3.31$; MNI 52, $-9,-23, \mathrm{t}=2.97$ ), right middle frontal gyrus (cluster size $=300$, MNI 39, 48, -12 , $\mathrm{t}=2.97$; MNI 46, 51, $-11, \mathrm{t}=2.94$ ), right hippocampus (cluster size=281, MNI 33, $-34,-8$, $\mathrm{t}=3.0$; MNI 34, $-27,-15, \mathrm{t}=2.94)$, left medial globus pallidus and parahippocampal gyrus (cluster size $=185, \mathrm{MNI}-12,-3,-15, \mathrm{t}=2.87$; MNI $-22,0,-18, \mathrm{t}=2.79$ ), right precuneus (cluster size $=146$, MNI 9, $-64,42, \mathrm{t}=3.19$; cluster size $=115$, MNI 25, $-60,52, \mathrm{t}=3.21)$ and the right superior temporal gyrus (cluster size=128, MNI 38, 6, -27, $\mathrm{t}=2.88$; MNI 44, 2, $-23, \mathrm{t}=2.77$ ). 


\section{FIGURE 1}

Grey matter volumes in participants with MCI varied little according to their insight grouping. Participants with impaired insight $(n=8)$ had decreased grey matter volume in the left (cluster size $=229, \mathrm{MNI}-15,-76,-57, \mathrm{t}=3.47)$ and right cerebellum (cluster size $=236, \mathrm{MNI}$ $9,-78,-27, \mathrm{t}=2.96$ and MNI $2,-78,-36, \mathrm{t}=2.96)$ compared with those who were overly concerned or appropriately aware of their cognitive deficits $(n=56)$.

The study however did not identify any major areas of grey matter volume difference between participants who were overly concerned about their deficits $(n=13)$ compared with those who had intact or impaired insight. Participants who were overly concerned had greater grey matter density in the right medial frontal lobe (cluster size $=254$, MNI $6,51,19, \mathrm{t}=4.01$ ) and the pyramis of the right cerebellum (cluster size $=224$, MNI $8,-73,-32, \mathrm{t}=3.33$ ) compared with those who lacked insight $(\mathrm{n}=8)$ although these differences were attenuated when they were compared to those with retained insight $(n=43)$ with only a small area of increased grey matter volume in the right middle frontal gyrus (cluster size=147, MNI 22, $-13,63, \mathrm{t}=3.16$ ).

Multiple regression analysis using insight as a continuous variable (Figure 2) revealed a single area of proportionally less grey matter in participants with decreased insight (cluster size $=795$ ) in the predominantly right (MNI 6, 50, 16, $\mathrm{t}=3.70$; MNI $6,45,25, \mathrm{t}=3.55)$ and to a lesser extent left medial frontal gyri (MNI 2, 38, 37, $\mathrm{t}=3.22$ ).

FIGURE 2 


\section{DISCUSSION}

The results of this cross-sectional study showed that older adults with MCI do not display significant grey matter loss compared with controls, although subtle regional losses are present, and affect predominantly temporal and anterior portions of the brain. Total grey matter volume was not associated with the degree of insight of participants with MCI, but regional losses in the medial frontal gyri were observed among those with impaired insight.

This study has a number of strengths and weaknesses that merit comment. As far as we are aware, this is the first study that has examined grey matter volume in association with the level of insight among people with MCI. Cognitive and insight status were ascertained by reliable methods and participants were classified according to acceptable criteria with good evidence base $[2,19]$.

We do acknowledge that the generalizability of our findings may be limited by the study of motivated volunteers, although by doing so we avoided the selection bias that is often introduced when recruitment is limited to clinic populations. We did not require our participants to have a history of cognitive decline over time that is sometimes required to establish a diagnosis of MCI. Our sample therefore could potentially represent milder disease and substantially more heterogeneity in the etiology of MCI than you would expect in clinical samples with a lower proportion expected to be in the prodromal stage of dementia or to progress to dementia over time. Our participants with MCI also did not differ significantly from controls in terms of their AQ-D discrepancy scores, suggesting a similar level of insight in both groups. Impaired insight was detected in only eight participants therefore small sample size was an issue. Informant reports could also be a source of potential bias and inaccuracy due to their own distress and potential cognitive impairment, however we did 
attempt to exclude participants with potentially unreliable informants. The cross-sectional design and lack of longitudinal imaging are further limitations.

We used standardized procedures and statistical methods to analyze the brain scans. Our analyses, however, were exploratory in nature and possibly prone to type 1 error. We tried to minimize the chance of a type 1 error by only accepting as significant brain regions associated with between-group differences greater than 100 voxels and p-values of 0.005 or less. We acknowledge however that the choice of threshold is somewhat arbitrary and none of the regions survived multiple comparison correction by using either a family-wise error (FWE) or false discovery rate (FDR) approach. Voxel-based morphometry studies such as ours are also prone to type 2 errors that may arise from a lack of power and changes in the shape or displacement of structures in the course of spatial normalization.

We found several brain regions of reduced grey matter volume in participants with MCI compared with controls, although these were predominantly located in the left medial temporal lobe (including the hippocampus and parahippocampal gyrus) and the left inferior/middle frontal region. The right temporal lobe was also affected, albeit to a lesser extent. These results are consistent with previous findings of decreased grey matter in predominantly medial temporal lobe structures $[25,26]$, although not with others that have showed decreased volume in the anterior and posterior cingulate gyrus in addition to medial temporal structures $[27,28]$.

A number of studies have investigated the neuropsychological determinants of impaired insight in patients with MCI and mild dementia with mixed findings of an association with severity of overall cognitive impairment or selective deficits in episodic memory or executive 
function $[14,29,30]$. It has been suggested that reduced insight is instead related to the individual's inability to assess their own cognitive functioning through the self-evaluation of success or failure in particular cognitive or behavioral tasks [31]. The individual therefore establishes a type of 'personal data base', which is then used to help monitor subsequent cognitive performance.

Neuroanatamical correlates of insight have been less studied and mostly limited to dementia patients. Rosen and colleagues [11] recruited 29 patients with dementia of varying etiologies but also included four patients with normal cognitive function and two with MCI. They assessed insight through self-appraisal of performance on cognitive testing. They found that self-appraisal accuracy was correlated with grey matter volume in the right orbitofrontal cortex in a similar location to our regression analysis. The only other VBM study in this area was carried out by Zamboni and colleagues [12] who found an association between grey matter loss in the posterior region of the right superior temporal sulcus and increasing anosognosia in a sample of 70 participants with frontotemporal dementia (FTD). We found an association between reduced insight of deficits and regional grey matter loss in the right frontal lobe but not in temporal structures as in the latter study, perhaps reflecting the differing patient populations studied.

Zamboni and colleagues completed a subsequent functional magnetic resonance imaging study where they recruited $17 \mathrm{MCI}$ patients, 17 probable Alzheimer's dementia (AD) patients and 17 age- and education-matched controls [32]. Imaging results showed significant differences in brain activation in medial prefrontal and anterior temporal regions in the AD participants but those with MCI did not differ from controls. 
Our findings are also consistent with other functional imaging studies in dementia patients suggesting that the frontal regions (especially right) are important in regulating self-awareness $[14,33]$. In addition, our findings are consistent with studies of insight in schizophrenic patients where smaller prefrontal grey matter volumes were found to be moderately associated with lower levels of insight $[34,35]$ although such findings have not always been consistent [36]. Neuroimaging studies in stroke patients have also consistently pointed to right brain regions (particularly prefrontal and parieto-temporal areas) as being essential in regulating self-awareness of neurological deficits [37].

In conclusion, in this cross-sectional study we found few differences between those with or without insight on a number of clinical and imaging parameters apart from subtle losses of grey matter in mainly anterior regions of the brain. Given the modest nature of these findings however, it would suggest that the routine assessment of insight in non-clinical MCI populations may not be useful. It would be helpful to design a larger prospective longitudinal study to explore this further in order to determine if reduced insight is predictive of brain atrophy and cognitive decline.

\section{ACKNOWLEDGMENTS}

This study was funded by the National Health and Medical Research Council of Australia, project grant number 353566. The authors thank Dr Ria Kotynia, Danyelle Cawood, Sue Hogan, Marina Lovasz, and Lynda McMullin for assistance with recruitment and participant assessment, Cheryl Ackoy for administrative assistance, Joanna Brisbane, Trish Knox, and M.J. Huang for laboratory assistance. The authors also thank the participants and their informants for taking part in this study. 


\section{REFERENCES}

[1] Winblad B, Palmer K, Kivipelto M, Jelic V, Fratiglioni L, Wahlund LO, Nordberg A, Backman L, Albert M, Almkvist O, Arai H, Basun H, Blennow K, de Leon M, DeCarli C, Erkinjuntti T, Giacobini E, Graff C, Hardy J, Jack C, Jorm A, Ritchie K, van Duijn C, Visser P, Petersen RC (2004) Mild cognitive impairment--beyond controversies, towards a consensus: report of the International Working Group on Mild Cognitive Impairment. J Intern Med 256, 240-246.

[2] Petersen RC, Smith GE, Waring SC, Ivnik RJ, Tangalos EG, Kokmen E (1999) Mild cognitive impairment: clinical characterization and outcome. Arch Neurol 56, 303-308.

[3] Russ TC, Morling JR (2012) Cholinesterase inhibitors for mild cognitive impairment. Cochrane Database Syst Rev 9, CD009132.

[4] Henry MS, Passmore AP, Todd S, McGuinness B, Craig D, Johnston JA (2013) The development of effective biomarkers for Alzheimer's disease: a review. Int J Geriatr Psychiatry 28, 331-340.

[5] Bischkopf J, Busse A, Angermeyer MC (2002) Mild cognitive impairment--a review of prevalence, incidence and outcome according to current approaches. Acta Psychiatr Scand 106, 403-414.

[6] Spalletta G, Girardi P, Caltagirone C, Orfei MD (2012) Anosognosia and neuropsychiatric symptoms and disorders in mild Alzheimer disease and mild cognitive impairment. J Alzheimers Dis 29, 761-772.

[7] Vogel A, Stokholm J, Gade A, Andersen BB, Hejl AM, Waldemar G (2004) Awareness of deficits in mild cognitive impairment and Alzheimer's disease: do MCI patients have impaired insight? Dement Geriatr Cogn Disord 17, 181-187. 
[8] Tremont G, Alosco ML (2011) Relationship between cognition and awareness of deficit in mild cognitive impairment. Int J Geriatr Psychiatry 26, 299-306.

[9] Tabert MH, Albert SM, Borukhova-Milov L, Camacho Y, Pelton G, Liu X, Stern Y, Devanand DP (2002) Functional deficits in patients with mild cognitive impairment: prediction of AD. Neurology 58, 758-764.

[10] Zamboni G, Wilcock G (2011) Lack of awareness of symptoms in people with dementia: the structural and functional basis. Int J Geriatr Psychiatry 26, 783-792.

[11] Rosen HJ, Alcantar O, Rothlind J, Sturm V, Kramer JH, Weiner M, Miller BL (2010) Neuroanatomical correlates of cognitive self-appraisal in neurodegenerative disease. Neuroimage 49, 3358-3364.

[12] Zamboni G, Grafman J, Krueger F, Knutson KM, Huey ED (2010) Anosognosia for behavioral disturbances in frontotemporal dementia and corticobasal syndrome: A voxel-based morphometry study. Dement Geriatr Cogn Disord 29, 88-96.

[13] Ries ML, Jabbar BM, Schmitz TW, Trivedi MA, Gleason CE, Carlsson CM, Rowley HA, Asthana S, Johnson SC (2007) Anosognosia in mild cognitive impairment: Relationship to activation of cortical midline structures involved in self-appraisal. J Int Neuropsychol Soc 13, 450-461.

[14] Vogel A, Hasselbalch SG, Gade A, Ziebell M, Waldemar G (2005) Cognitive and functional neuroimaging correlate for anosognosia in mild cognitive impairment and Alzheimer's disease. Int J Geriatr Psychiatry 20, 238-246.

[15] Greenop KR, Xiao J, Almeida OP, Flicker L, Beer C, Foster JK, van Bockxmeer FM, Lautenschlager NT (2011) Awareness of cognitive deficits in older adults with cognitive-impairment-no-dementia (CIND): comparison with informant report. Alzheimer Dis Assoc Disord 25, 24-33. 
[16] Morris JC, Heyman A, Mohs RC, Hughes JP, van Belle G, Fillenbaum G, Mellits ED, Clark C (1989) The Consortium to Establish a Registry for Alzheimer's Disease (CERAD). Part I. Clinical and neuropsychological assessment of Alzheimer's disease. Neurology 39, 1159-1165.

[17] Knopman DS, Roberts RO, Geda YE, Pankratz VS, Christianson TJ, Petersen RC, Rocca WA (2010) Validation of the telephone interview for cognitive statusmodified in subjects with normal cognition, mild cognitive impairment, or dementia. Neuroepidemiology 34, 34-42.

[18] Yesavage JA, Brink TL, Rose TL, Lum O, Huang V, Adey M, Leirer Vo (1982) Development and validation of a geriatric depression screening scale: a preliminary report. J Psychiatr Res 17, 37-49.

[19] Migliorelli R, Teson A, Sabe L, Petracca G, Petracchi M, Leiguarda R, Starkstein SE (1995) Anosognosia in Alzheimer's disease: a study of associated factors. $J$ Neuropsychiatry Clin Neurosci 7, 338-344.

[20] Folstein MF, Folstein SE, McHugh PR (1975) "Mini-mental state". A practical method for grading the cognitive state of patients for the clinician.J Psychiatr Res 12, 189-198.

[21] Mohs RC, Cohen L (1988) Alzheimer's Disease Assessment Scale (ADAS). Psychopharmacol Bull 24, 627-628.

[22] Hixson JE, Vernier DT (1990) Restriction isotyping of human apolipoprotein E by gene amplification and cleavage with HhaI. J Lipid Res 31, 545-548.

[23] Araki A, Sako Y (1987) Determination of free and total homocysteine in human plasma by high-performance liquid chromatography with fluorescence detection. J Chromatogr 422, 43-52. 
[24] Ridgway GR, Omar R, Ourselin S, Hill DL, Warren JD, Fox NC (2009) Issues with threshold masking in voxel-based morphometry of atrophied brains. Neuroimage 44, 99-111.

[25] Pennanen C, Testa C, Laakso MP, Hallikainen M, Helkala EL, Hanninen T, Kivipelto M, Kononen M, Nissinen A, Tervo S, Vanhanen M, Vanninen R, Frisoni GB, Soininen H (2005) A voxel based morphometry study on mild cognitive impairment. J Neurol Neurosurg Psychiatry 76, 11-14.

[26] Meyer P, Feldkamp H, Hoppstadter M, King AV, Frolich L, Wessa M, Flor H (2013) Using Voxel-Based Morphometry to Examine the Relationship between Regional Brain Volumes and Memory Performance in Amnestic Mild Cognitive Impairment. Front Behav Neurosci 7, 89.

[27] Trivedi MA, Wichmann AK, Torgerson BM, Ward MA, Schmitz TW, Ries ML, Koscik RL, Asthana S, Johnson SC (2006) Structural MRI discriminates individuals with Mild Cognitive Impairment from age-matched controls: a combined neuropsychological and voxel based morphometry study. Alzheimers Dement 2, 296-302.

[28] Wang Z, Guo X, Qi Z, Yao L, Li K (2010) Whole-brain voxel-based morphometry of white matter in mild cognitive impairment. Eur J Radiol 75, 129-133.

[29] Reed BR, Jagust WJ, Coulter L (1993) Anosognosia in Alzheimer's disease: relationships to depression, cognitive function, and cerebral perfusion. J Clin Exp Neuropsychol 15, 231-244.

[30] Kashiwa Y, Kitabayashi Y, Narumoto J, Nakamura K, Ueda H, Fukui K (2005) Anosognosia in Alzheimer's disease: association with patient characteristics, psychiatric symptoms and cognitive deficits. Psychiatry Clin Neurosci 59, 697704. 
[31] Hannesdottir K, Morris RG (2007) Primary and secondary anosognosia for memory impairment in patients with Alzheimer's disease. Cortex 43, 1020-1030.

[32] Zamboni G, Drazich E, McCulloch E, Filippini N, Mackay CE, Jenkinson M, Tracey I, Wilcock GK (2013) Neuroanatomy of impaired self-awareness in Alzheimer's disease and mild cognitive impairment. Cortex 49, 668-678.

[33] Starkstein SE, Vazquez S, Migliorelli R, Teson A, Sabe L, Leiguarda R (1995) A single-photon emission computed tomographic study of anosognosia in Alzheimer's disease. Arch Neurol 52, 415-420.

[34] Sapara A, Cooke M, Fannon D, Francis A, Buchanan RW, Anilkumar AP, Barkataki I, Aasen I, Kuipers E, Kumari V (2007) Prefrontal cortex and insight in schizophrenia: a volumetric MRI study. Schizophr Res 89, 22-34.

[35] Flashman LA, McAllister TW, Johnson SC, Rick JH, Green RL, Saykin AJ (2001) Specific frontal lobe subregions correlated with unawareness of illness in schizophrenia: a preliminary study. J Neuropsychiatry Clin Neurosci 13, 255-257.

[36] Bassitt DP, Neto MR, de Castro CC, Busatto GF (2007) Insight and regional brain volumes in schizophrenia. Eur Arch Psychiatry Clin Neurosci 257, 58-62.

[37] Orfei MD, Robinson RG, Prigatano GP, Starkstein S, Rusch N, Bria P, Caltagirone C, Spalletta G (2007) Anosognosia for hemiplegia after stroke is a multifaceted phenomenon: a systematic review of the literature. Brain 130, 3075-3090. 
Table 1. Comparison of participants with MCI and controls

\begin{tabular}{|c|c|c|c|c|}
\hline Variable & $\begin{array}{l}\text { Controls } \\
(n=55)\end{array}$ & $\operatorname{MCI}(n=65)$ & Statistic & $\mathrm{P}$ value \\
\hline $\begin{array}{l}\text { Age, median } \\
\text { (IQR) }\end{array}$ & $75(71-79)$ & $70(69-74)$ & $\mathrm{z}=3.43$ & $<0.001$ \\
\hline $\begin{array}{l}\text { Male gender, } n \\
(\%)\end{array}$ & $29(52.7)$ & $30(46.2)$ & $\chi^{2}=0.52$ & 0.473 \\
\hline $\begin{array}{l}\text { Education in } \\
\text { years, mean } \\
\text { (SD) }\end{array}$ & $11.7(2.9)$ & $11.2(3.2)$ & $\mathrm{t}=0.99$ & 0.320 \\
\hline $\begin{array}{l}\text { APOE } 4 \\
\text { carrier, n (\%) }\end{array}$ & $16(29.1)$ & $22(33.8)$ & $\chi^{2}=0.31$ & 0.577 \\
\hline $\begin{array}{l}\text { SF36 mental } \\
\text { score, median } \\
\text { (IQR) }\end{array}$ & $59.9(57-62.5)$ & $56.8(50-59.7)$ & $\mathrm{z}=3.52$ & $<0.001$ \\
\hline $\begin{array}{l}\text { IQ, median } \\
\text { (IQR) }\end{array}$ & $119(115-123)$ & $114(111-118)$ & $\mathrm{z}=3.99$ & $<0.001$ \\
\hline $\begin{array}{l}\text { ADAS-cog, } \\
\text { mean (SD) }\end{array}$ & $6.4(3.1)$ & $10.5(4.2)$ & $\mathrm{t}=-6.07$ & $<0.001$ \\
\hline $\begin{array}{l}\text { MMSE, } \\
\text { median (IQR) }\end{array}$ & $29(28-30)$ & $28(27-29)$ & $z=2.92$ & 0.004 \\
\hline $\begin{array}{l}\text { AQ-D } \\
\text { discrepancy } \\
\text { score, mean }\end{array}$ & $-7.4(6)$ & $-9.3(8.1)$ & $\mathrm{t}=1.43$ & 0.154 \\
\hline $\begin{array}{l}\text { B12, median } \\
\text { (IQR) }\end{array}$ & $326(250-443)$ & $307(235-407)$ & $\mathrm{z}=0.79$ & 0.431 \\
\hline $\begin{array}{l}\text { Folate, mean } \\
\text { (SD) }\end{array}$ & $1546(687)$ & $1379(685)$ & $\mathrm{t}=1.33$ & 0.187 \\
\hline $\begin{array}{l}\text { tHcy, median } \\
\text { (IQR) }\end{array}$ & $10.6(7.5-11.9)$ & $10.7(8.5-13.3)$ & $\mathrm{z}=-1.31$ & 0.191 \\
\hline $\begin{array}{l}\text { GM volume, } \\
\text { mean (SD) }\end{array}$ & $451.8(52)$ & $460.4(53.5)$ & $\mathrm{t}=-0.89$ & 0.376 \\
\hline \multicolumn{5}{|c|}{$\begin{array}{l}\text { Abbreviations: MCI - mild cognitive impairment, IQR - interquartile range, SD - standard } \\
\text { deviation, APOE - apolipoprotein E, IQ - intelligence quotient, ADAS-cog - Alzheimer's } \\
\text { Disease Assessment Scale -Cognitive Subscale, MMSE - Mini-Mental State Examination, } \\
\text { AQ-D - Anosognosia Questionnaire-Dementia, B12 - vitamin B12, tHcy - total } \\
\text { plasma homocysteine, GM - grey matter }\end{array}$} \\
\hline
\end{tabular}


Table 2. Comparison of participants according to insight categories

\begin{tabular}{|c|c|c|c|c|}
\hline Variable & Intact $(n=43)$ & $\begin{array}{l}\text { Overly } \\
\text { concerned } \\
(\mathrm{n}=13)\end{array}$ & Impaired $(n=8)$ & $P$ value \\
\hline $\begin{array}{l}\text { Age, median } \\
\text { (IQR) }\end{array}$ & $70(69-74)$ & $70(68-73)$ & $73(69-80)$ & 0.531 \\
\hline $\begin{array}{l}\text { Male gender, } n \\
(\%)\end{array}$ & $21(48.8)$ & $6(46.2)$ & $3(37.5)$ & 0.839 \\
\hline $\begin{array}{l}\text { Education in } \\
\text { years, mean } \\
\text { (SD) }\end{array}$ & $11.8(3)$ & $10.2(3.7)$ & $9.8(2.8)$ & 0.112 \\
\hline $\begin{array}{l}\text { APOE } 4 \\
\text { carrier, n (\%) }\end{array}$ & $16(37.2)$ & $4(30.8)$ & $1(12.5)$ & 0.387 \\
\hline $\begin{array}{l}\text { SF36 mental } \\
\text { score, mean } \\
\text { (SD) }\end{array}$ & $55.6(7)$ & $51.5(7.9)$ & $54.6(10.2)$ & 0.239 \\
\hline $\begin{array}{l}\text { ADAS-cog, } \\
\text { mean (SD) }\end{array}$ & $10.3(3.7)$ & $11(5.8)$ & $10.9(4.4)$ & 0.847 \\
\hline $\begin{array}{l}\text { MMSE, } \\
\text { median (IQR) }\end{array}$ & $28(26-29)$ & $27(26-28)$ & $28(25-29)$ & 0.475 \\
\hline $\begin{array}{l}\text { tHcy, median } \\
\text { (IQR) }\end{array}$ & $11.1(8.7-13.8)$ & $8.8(7.8-9.4)$ & $\begin{array}{l}12.6(10.9- \\
13.9)\end{array}$ & 0.006 \\
\hline $\begin{array}{l}\text { GM volume, } \\
\text { mean (SD) }\end{array}$ & $461.1(56.4)$ & $455.5(44.3)$ & $465.5(60.5)$ & 0.913 \\
\hline \multicolumn{5}{|c|}{$\begin{array}{l}\text { Abbreviations: IQR - interquartile range, SD - standard deviation, APOE - apolipoprotein } \\
\text { E, ADAS-cog - Alzheimer's Disease Assessment Scale -Cognitive Subscale, MMSE - } \\
\text { Mini-Mental State Examination, tHcy - total plasma homocysteine, GM - grey } \\
\text { matter } \\
\text { Note: Please see supplementary table S1 reporting these associations using } \\
\text { awareness of deficit scores as a continuous variable. }\end{array}$} \\
\hline
\end{tabular}




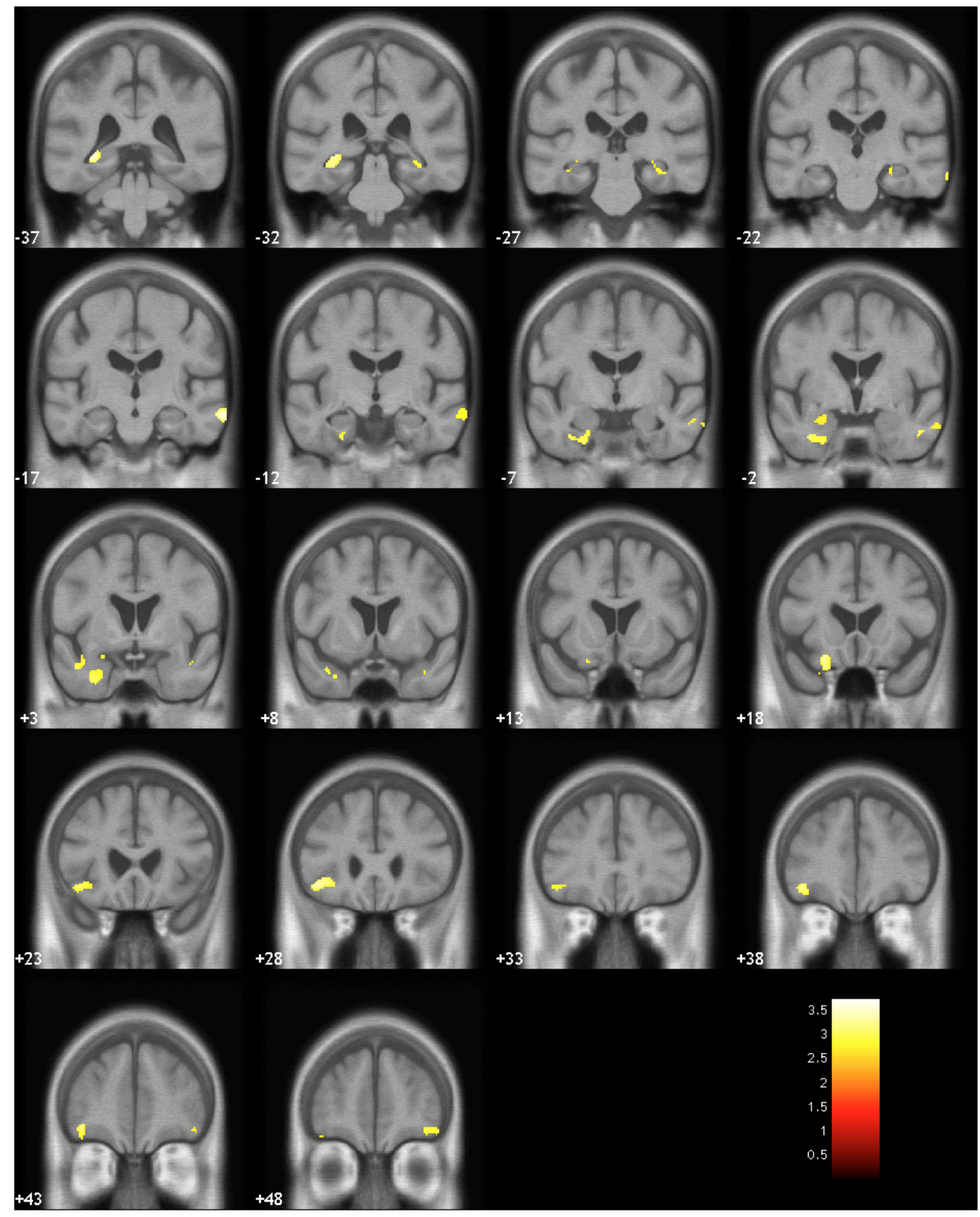

Figure 1. Grey matter density according to MCI status. This figure shows regions

(overlaid on a mean image of the dataset) where control participants had higher grey matter volume than those with MCI (voxel-wise thresholded at $\mathrm{p}<0.005$, uncorrected for multiple comparisons). Age and intracranial volume were included as covariates in the analysis. The color bar represents the T-values and illustrates the magnitude of the significance with white (upper portion of the color palette) being the greatest. 

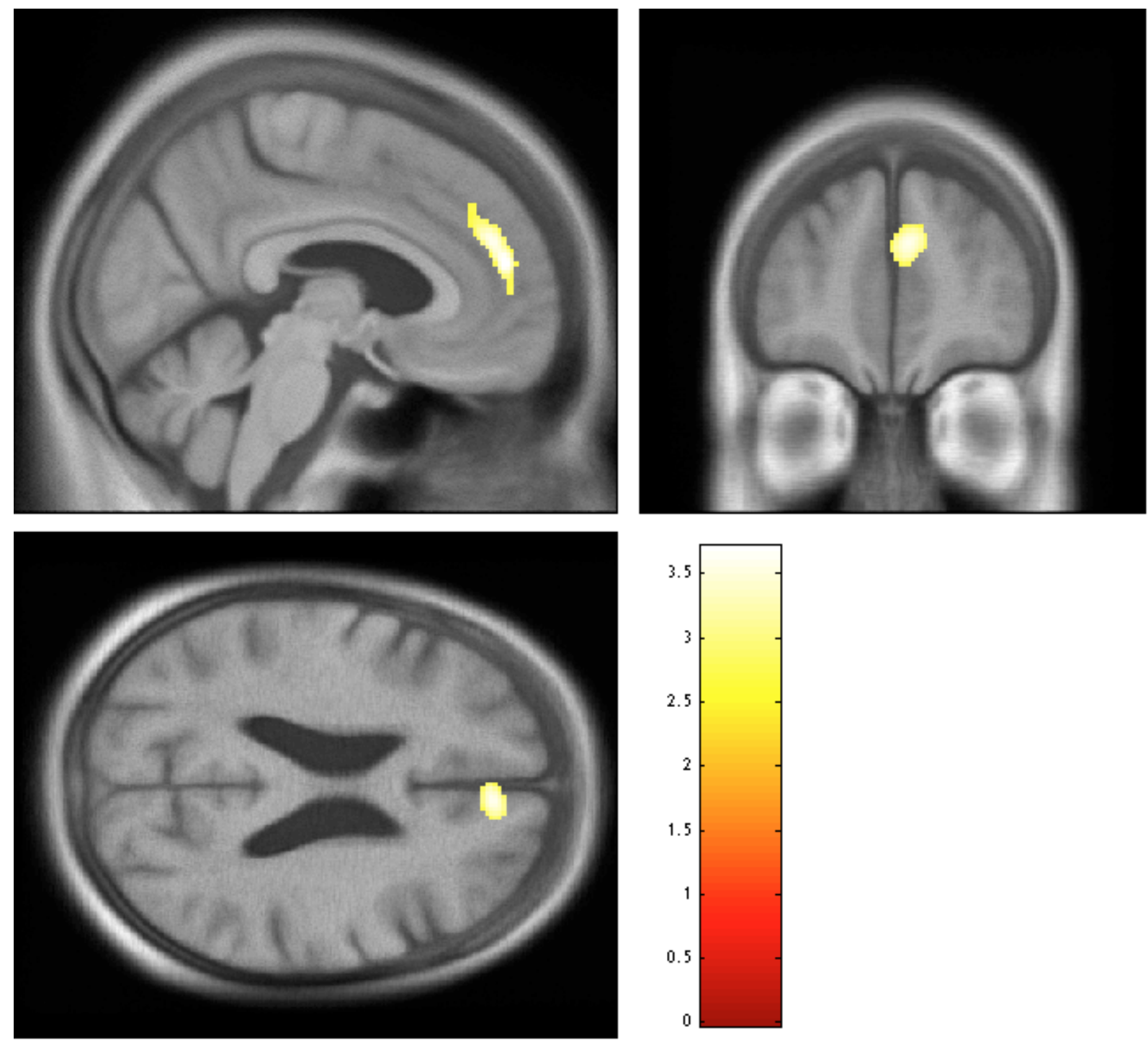

Figure 2. Grey matter density according to degree of insight. This figure shows regions

(overlaid on a mean image of the dataset) where reduced insight was associated with proportionally lower grey matter volume (voxel-wise thresholded at $\mathrm{p}<0.005$, uncorrected for multiple comparisons). Age and intracranial volume were included as covariates in the analysis. The color bar represents the T-values and illustrates the magnitude of the association with white (upper portion of the color palette) being the greatest. 